\title{
Caracterização de genótipos de trigo do bloco de cruzamento da Embrapa Trigo, RS, Brasil
}

\author{
Characterization of wheat genotypes from the crossing block of the national wheat \\ research center, RS, Brazil
}

\section{Gilberto Peripolli Bevilaqua $^{1}$ Aroldo Gallon Linhares ${ }^{1}$ Cantídio Nicolau Alves de Sousa ${ }^{1}$}

\section{RESUMO}

No Centro Nacional de Pesquisa de Trigo (CNPT - Embrapa Trigo), em 1999, genótipos de trigo integrantes do bloco de cruzamento foram avaliados quanto à altura de planta, à duração do ciclo até o espigamento, ao comprimento do pedúnculo e ao número de grãos por espiga. Relacionando essas características, foram estudados 122 genótipos em duas épocas de semeadura, que consistiram os blocos. Foram medidos dez pedúnculos do afilho principal, de cada genótipo, e contou-se o número total de grãos de cada espiga. Para a apresentação dos resultados, foram considerados os valores médios dessas avaliações. Para a análise estatística, considerou-se o experimento como blocos casualizados. Dos resultados obtidos, concluiu-se que os genótipos de trigo BR 18, BR 42 e Sonora 64 destacam-se por porte baixo e ciclo precoce, enquanto Florida 301 e "Trigo de chapéu" destacam-se por porte alto e ciclo longo até o espigamento. A altura de planta mostra elevada correlação com comprimento do pedúnculo e duração do ciclo até o espigamento, e esta, com o comprimento de pedúnculo. Os genótipos de trigo CNT 10 e PF 92130 são indicados com finalidades artesanais por suas características de pedúnculo longo e número de grãos por espiga acima da média. $O$ estudo mostra grande variabilidade genotipica em trigo quanto às características avaliadas, fornecendo informações sobre os genótipos que poderão ser utilizados por melhoristas, técnicos e agricultores.

Palavras-chave: Triticum aestivum, ciclo, altura, fertilidade de espiga.

\section{ABSTRACT}

Wheat genotypes from the crossing block were caracterized at the National Wheat Research Center (Embrapa
Trigo) in 1999. Plant traits evaluated were height, cycle up to heading, peduncle length, and number of grains per spike. One hundred and twenty-two genotypes were evaluated at two seeding dates that consisted blocks. For each tretament, ten peduncles from the main tiller were measured and the total number of grain in each spike was counted. The mean values obtained in such evaluations were take into consideration for presenting the results. For statistical analysis, the experiment was considered complete block design. Based upon results the genotypes BR 18, BR 42 and Sonora 64 were outstanding for their low stature and early cycle. Florida 301 and "Trigo de chapéu" were outstanding for their high stature and long cycle up to heading. The plant height showed a high correlation with peduncle lenght and cycle up to heading, and the latter correlated with peduncle lenght. The genotypes CNT 10 and PF 92130 can be indicated for handicraft finalities due to the long peduncle and spike grain number above average. The study showed a considerable genotipic variability among wheat genotypes as to the traits assessed and provided information on wheat genotypes that may be used for breeding and commercial production.

Key words: Triticum aestivum, cycle, height, spike fertility.

\section{INTRODUÇÃO}

Anualmente o Centro Nacional de Pesquisa de Trigo (CNPT - Embrapa Trigo), em Passo Fundo, RS, é responsável pela instalação de parcelas, em campo, correspondentes a genótipos eleitos para comporem o bloco de cruzamentos (BC) de trigo. $\mathrm{O}$ conhecimento mais detalhado das características desses genótipos é importante no sentido de oferecer

'Engenheiro Agrônomo, Pesquisador da Embrapa clima temperado. CP 403, 99001-970, Pelotas-RS. E-mail:bevilaq@ cpat.embrapa.br Autor para correspondência. 
mais subsídios aos melhoristas para programarem os cruzamentos, visando à seleção genética de novas combinações (LINHARES et al., 1997). Para tanto, é necessário um banco de dados sobre as principais características dos genótipos de trigo constantes do BC (SILVA et al., 1998). Neste sentido, informações de altura dos genótipos são importantes para seleção de genitores mais baixos, com menor suscetibilidade ao acamamento, assim como, informações sobre o número de grãos por espiga, referido como importante componente no rendimento final de lavouras de cereais (SHAKIBA et al., 1996).

Em trigo, a relação entre peso de grãos e da massa seca da parte aérea, referida como índice de colheita, foi estudada por diversos autores que analisaram esse efeito sobre o rendimento final da cultura (NEDEL, 1994; SLAFER \& ANDRADE, 1991). As cultivares de trigo mais antigas, inclusive aquelas utilizadas no Rio Grande do Sul, caracterizavam-se por apresentar porte alto, com maior suscetibilidade ao acamamento e, geralmente, apresentavam menor número de grãos por espiga. Por outro lado, cultivares modernas caracterizamse pelo porte mais baixo e maior número de grãos por espiga (NEDEL, 1994; RODRIGUES, 2000). Da mesma maneira, FRANCO \& CARVALHO (1987) e RODRIGUES (2000) observaram que o incremento do potencial de produtividade obtido pelo melhoramento genético esteve associado à expressiva participação do número de grãos por espiga.

COX et al. (1988) e AUSTIN et al. (1989) observaram que número de grãos por área, obtido pelo número de grãos por espiga e número de espigas por área, foi o componente mais importante na determinação da produtividade de lavouras de trigo, mostrando a maior correlação positiva com o rendimento de grãos. Em arroz, o componente de rendimento número de grãos por panícula foi o mais importante na definição da produtividade, sendo o componente a ser priorizado durante o processo de melhoramento e seleção de novas cultivares (ZAFFARONI et al., 1998). Em trigo, o potencial de rendimento da lavoura parece ser mais limitado pelos drenos (número de grãos $/ \mathrm{m}^{2}$ ) do que pela fonte (capacidade da cultura para abastecer esses drenos) (RODRIGUES, 2000).

BORREL et al. (1993), citados por SHAKIBA et al. (1996), comparando, sob condições de campo, dois genótipos de trigo quase isogênicos, sendo um alto e um semi-anão, estimaram a possível contribuição das reservas do pedúnculo e do penúltimo entre-nó, para o rendimento final de grãos da planta, em 10,2 e 8,4 \% respectivamente. Segundo CRUZAGUADO et al. (1989), especial atenção deveria ser dada para os colmos da planta devido à competição que existe entre o crescimento dos entre-nós superiores e dos órgãos reprodutivos, nas semanas anteriores à antese. De outra forma, para SIDIQUE et al. (1989), a seleção para elevada relação de peso e de tamanho de espiga em relação ao colmo poderia conduzir a um aumento na produtividade de grãos. $\mathrm{O}$ aumento de rendimento dos genótipos antigos em relação aos modernos, deveu-se ao aumento do índice de colheita e/ou do rendimento biológico (quantidade de massa seca da parte aérea de planta) das cultivares (RODRIGUES, 2000).

Paralelamente aos caracteres comentados acima, neste trabalho, visou-se identificar, através de maior comprimento do pedúnculo, genótipos mais adequados ao uso da palha em trabalhos artesanais. Os genótipos comumente usados com finalidade artesanal, na região de Passo Fundo, para confeção de chapéus, cestas, entre outros produtos, foram selecionados dentre aqueles que, numa certa época, foram trazidos a determinada comunidade agrícola e ali cultivados ao longo dos anos. Assim, é possível que tipos mais vantajosos, desenvolvidos pela pesquisa nos últimos anos, possam substituir aqueles, trazendo mais benefícios em termos de manejo da cultura, do uso da palha em si, e ainda, do aproveitamento do grão para fins alimentares.

Os objetivos deste trabalho foram avaliar os genótipos de trigo, componentes do bloco de cruzamentos do CNPT - Embrapa Trigo, em 1999, quanto à duração do ciclo até o espigamento, à altura de planta, ao comprimento do pedúnculo e ao número de grãos por espiga, visando quantificar essas características para fins de contribuição ao estudo do comportamento genotípico quanto à relação grão/palha, bem como identificar genótipos com maior comprimento de pedúnculo, característica buscada para uso da palha para fins artesanais.

\section{MATERIAL E MÉTODOS}

Foram analisados estatisticamente os dados correspondentes a 122 genótipos (Tabela 1) integrantes do BC do CNPT - Embrapa Trigo, em 1999, relacionando altura de planta, duração de ciclo até o espigamento, comprimento de pedúnculo e número de grãos por espiga. Esta última característica foi avaliada em apenas 79 genótipos, devido a problemas climáticos. 
O bloco de cruzamento foi conduzido em Latossolo Vermelho Escuro distrófico, no campo experimental do CNPT - Embrapa Trigo, em parcelas de três linhas com três metros de comprimento, espaçadas $0,20 \mathrm{~m}$ entre linhas e com população de 250 plantas por metro quadrado. A semeadura foi efetuada em duas épocas, $1^{\circ}$ e 28 de junho. A adubação e o controle de doenças foram realizados de acordo com as indicações técnicas preconizadas para a cultura (REUNIÃO..., 1999).

Para duração do ciclo até o espigamento, foi observado o período, em dias, da emergência de plântulas até a emissão da espiga em 50 \% das plantas da parcela. Para altura de planta, foram medidas dez plantas no centro da parcela, na fase de maturação. $\mathrm{O}$ comprimento do pedúnculo foi avaliado em dez colmos, colhidos na linha externa da parcela na fase inicial de maturação (amarelecimento da planta), dando-se preferência a colmos do perfilho principal da planta. O número de grãos por espiga foi avaliado em dez espigas colhidas do perfilho principal, debulhadas manualmente, contando-se o número total de grãos obtidos por espiga. As medidas e contagens foram efetuadas em laboratório.

Para a análise estatística, foi usado o modelo de blocos casualizados e cada época foi considerada uma repetição. Para separação das médias, foi empregado o teste de desvio padrão, em que os genótipos foram classificados como superior (s) ou inferior (i), conforme o valor da média mais ou menos um desvio padrão, conforme o caso. Foi ainda utilizada a correlação simples entre as variáveis (SAS, 1985).

\section{RESULTADOS E DISCUSSÃO}

Analisando-se os dados de altura de planta, os genótipos BR 18, BR 42, Calidad, Karim, OR 1, PF 950295, PF 960170, PF 973571 e Sonora 64 apresentaram menor altura de planta. Por outro lado, os genótipos BR 8, CEP 24, CNT 10, Florida 301, Frontana, Jacuí, PF 869114, PF 950338, PF 979020, RS 1 e "Trigo de chapéu" mostraram-se com altura de planta mais elevada (Tabela 1). COX et al. (1988) e AUSTIN et al. (1989), estudando a cultura de trigo, respectivamente, nos Estados Unidos e na GrãBretanha, atestam que o aumento em rendimento de grãos de trigo, ao longo do último século, deveu-se a um aumento no índice de colheita e no rendimento biológico dos genótipos modernos. Neste sentido, genótipos com maior rendimento biológico mas resistentes ao acamamento seriam desejáveis em relação àquelas com porte baixo, embora esta seja uma característica apreciada pelos agricultores.

Para a duração do ciclo até o espigamento, os genótipos BR 18, BR 42, Calidad, Frocor-P, PF 8597, PF 92350, PF 940301, PF 940305, Pitana, Sonora 64 e Spica-LP 942 apresentaram ciclo precoce, enquanto os genótipos Florida 301, IPF 71392, PF 93113, PF 93167, PF 940042, PF 940262, PF 940353, PF 960016, PF 960018, PF 960020, PF 960177, PF 960366 e "Trigo de chapéu" apresentaram ciclo longo até o espigamento. O ciclo precoce é característica desejável em trigo, entretanto, NEDEL (1994) afirma que genótipos modernos, lançadas para cultivo no Brasil após 1980, apresentaram período da emergência ao espigamento 3 a 4 dias mais longo que cultivares antigas (lançadas até 1970). Entretanto, diferenças de ciclo até o espigamento, entre genótipos, é estratégia que agricultores podem utilizar para reduzir perdas por geada. Assim, genótipos que apresentam ciclo longo são adequados para plantio antecipado ou para duplo propósito.

Os genótipos BR 18, BR 42 e Sonora 64 destacaram-se por apresentar porte baixo e ciclo precoce. Segundo SOUSA (1997), a cultivar BR 42, produto de retrocruzamento realizado no Brasil, usando a cultivar mexicana Jupateco 73 como genitor recorrente, e a cultivar Sonora 64, introduzida diretamente do Centro Internacional de Melhoramento de Milho e Trigo (CIMMYT), destacaram-se como ciclo precoce e porte baixo. Por outro lado, os genótipos Florida 301 e "Trigo de chapéu" destacaram-se como porte alto e ciclo longo até o espigamento.

Para comprimento de pedúnculo, os genótipos CEP 24, CNT 10, Fuging 5114, IPF 71392, Jacuí, LE 236, PF 92130, PF 940042, PF 960016, RS-1 e "Trigo de chapéu" apresentaram pedúnculo longo, e podem ser indicados com finalidades artesanais. Pode-se destacar os genótipos CNT 10 e PF 92130 como preferenciais ao uso artesanal, pois apresentaram número de grãos por espiga acima da média geral do experimento. Os genótipos BR 35, BRS 179, Cunningham, Granito, IPF 71345, Klein H3450C3131, OR 1, PF 950295, PF 970241, PF 973571 e Sonora 64 apresentaram pedúnculo curto. Segundo SHAKIBA et al. (1996), maior comprimento de pedúnculo, pode interferir em mais de $10 \%$ no rendimento de grãos da lavoura e poderia ser uma característica desejável no 
Tabela 1 - Dados de pedigree, altura de planta, duração do ciclo até o espigamento, comprimento de pedúnculo (CPed) e número de grãos por espiga de genótipos de trigo (Triticum aestivum) do bloco de cruzamento. Passo Fundo, 1999.

\begin{tabular}{|c|c|c|c|c|c|}
\hline Genótipos & Pedigree & $\begin{array}{c}\text { Altura } \\
(\mathrm{cm})\end{array}$ & $\begin{array}{l}\text { Ciclo } \\
\text { (dias) }\end{array}$ & $\begin{array}{l}\text { CPed } \\
(\mathrm{cm})\end{array}$ & $\mathrm{N}^{0}$ de grãos \\
\hline Antizana Sib & Ciano sib/Gallo & 78 & 89 & 33 & - \\
\hline Bagula Sib & Teeter/Junco & 78 & 90 & 29 & 29 \\
\hline BDZA 593 & Desconhecido & 83 & 87 & 37 & - \\
\hline BH 1146 & Fronteira/Mentana//PG 1 & 95 & 89 & 30 & - \\
\hline BR 8 & IAS 20/Toropi//PF 70100 & $100 \mathrm{i}$ & 93 & 37 & - \\
\hline BR 15 & IAS 54*2/Tokai 80//PF 69193 & 85 & 94 & 30 & 25 \\
\hline BR 18 & D 6301/Nainari 60//Weique Red Mace/3/Ciano*2/Chris & $70 \mathrm{~s}$ & $82 \mathrm{~s}$ & 30 & - \\
\hline BR 23 & Corre Caminos/Alondra sib/3/IAS 54-20/Cotipora//CNT 8 & 83 & 91 & 34 & 22 \\
\hline BR 35 & IAC $5 * 2 / 3 /$ CNT $7 * 3 /$ Londrina//IAC 5/Hadden & 88 & 90 & $27 \mathrm{i}$ & 22 \\
\hline BR 42 & Jupateco $73 * 6 / /$ Lagoa Vermelha*5/Agatha & $73 \mathrm{~s}$ & $84 \mathrm{~s}$ & 30 & - \\
\hline BRS 49 & BR 35/PF 83619//PF 858/PF 8550 & 90 & 92 & 31 & $31 \mathrm{~s}$ \\
\hline BRS 119 & PF 82252/BR 35//IAPAR 17/PF 8550 & 93 & 90 & 28 & - \\
\hline BRS 120 & PF 83899/PF 813//F 27141 & 90 & 94 & 34 & 28 \\
\hline BRS 177 & PF 83899/PF 813//F 27141 & 93 & 97 & 37 & 27 \\
\hline BRS 179 & BR 35/PF 8596/3/PF 772003*2/PF 813//PF 83899 & 88 & 95 & $25 \mathrm{i}$ & 25 \\
\hline BRS 194 & CEP 14/BR 23//CEP 19 & 80 & 91 & 29 & - \\
\hline Calidad & TZPP/Sonora 64/3/Lerma Rojo 64A/TZPP//ANDES E & $70 \mathrm{~s}$ & $82 \mathrm{~s}$ & 31 & - \\
\hline CEP 24 & BR 3/CEP 7887//CEP 7775/CEP 11 & $100 \mathrm{i}$ & 94 & $40 \mathrm{~s}$ & - \\
\hline CEP 27 & CEP 8057/Butuí//CEP 8324 & 83 & 92 & 28 & 25 \\
\hline CNT 10 & IAS 46/IAS 49//IAS 46/Tokai 66 & $110 \mathrm{i}$ & 96 & $39 \mathrm{~s}$ & 26 \\
\hline Cotrirosa & (=Tucunduva 77 ) & 98 & 86 & 37 & - \\
\hline Cunningham & - & 78 & 95 & $27 \mathrm{i}$ & 26 \\
\hline Embrapa 16 & Hulha Negra/CNT 7//Amigo/CNT 7 & 80 & 91 & 32 & - \\
\hline Embrapa 27 & PF 83743//PF 83182/F 25716 & 88 & 95 & 34 & 24 \\
\hline Embrapa 40 & $\mathrm{PF} 7650 / \mathrm{NS}$ 18-78//CNT 8/PF 7577 & 93 & 91 & 31 & 27 \\
\hline Florida 301 & - & $100 \mathrm{i}$ & $102 \mathrm{i}$ & 31 & 23 \\
\hline Frocor-P & Frontana/C.O.C.R. (La Estanzuela) & 83 & $78 \mathrm{~s}$ & 35 & - \\
\hline Frontana & Fronteira/Mentana & $108 \mathrm{i}$ & 90 & 35 & $20 \mathrm{i}$ \\
\hline Fufan 3276 & - & 90 & 89 & 36 & - \\
\hline Fuging 5114 & - & 83 & 91 & $39 \mathrm{~s}$ & - \\
\hline Fundacep 29 & BR 23/CEP 8423//Buck sib & 83 & 90 & 36 & - \\
\hline Fundacep 30 & BR 32/CEP 21//Ciano 79 & 78 & 94 & 35 & 27 \\
\hline Granito & PF 869107/Klein H3450 C3131 & 83 & 98 & $27 \mathrm{i}$ & 23 \\
\hline IAPAR 53 & Sulino/IA 7929 & 80 & 90 & 29 & 27 \\
\hline IPF 58950 & Teeter/Junco & 78 & 90 & 28 & $30 \mathrm{~s}$ \\
\hline IPF 71327 & Chumb 18/Bagula sib & 78 & 91 & 28 & - \\
\hline IPF 71345 & NG 8319//Shangai 4/Lira & 78 & 92 & $26 \mathrm{i}$ & 28 \\
\hline IPF 71392 & Altar 84/Aegilops squarrosa & 98 & $113 \mathrm{i}$ & $43 \mathrm{~s}$ & 23 \\
\hline IPF 71457 & Chumb 18/Bagula sib & 80 & 91 & 32 & 29 \\
\hline IPR 84 & Anahuac 75/PF 7455//PF 72556/3/Pamir sib/Ald//Kavka sib & 88 & 92 & 35 & 24 \\
\hline Jacui & Colatana 824-51/Yaktana 54//Carazinho/3/Toropi & $108 \mathrm{i}$ & 98 & $44 \mathrm{~s}$ & 22 \\
\hline
\end{tabular}

$(\mathrm{s})=$ superior e (i)=inferior, em relação a média mais ou menos um desvio padrão.

Ciência Rural, v. 33, n. 5, set-out, 2003. 
Tabela 1 - Continuação.

\begin{tabular}{|c|c|c|c|c|c|}
\hline Genótipos & Pedigree & $\begin{array}{c}\text { Altura } \\
(\mathrm{cm})\end{array}$ & $\begin{array}{l}\text { Ciclo } \\
\text { (dias) }\end{array}$ & $\begin{array}{l}\text { CPed } \\
(\mathrm{cm})\end{array}$ & $\mathrm{N}^{o}$ de grãos \\
\hline Karim & Jo sib/AA sib//FG sib & $70 \mathrm{~s}$ & 91 & 30 & $15 \mathrm{i}$ \\
\hline Klein H29604-12100 & - & 80 & 96 & 28 & $13 \mathrm{i}$ \\
\hline Klein H3450-C3131 & - & 78 & 97 & $27 \mathrm{i}$ & 25 \\
\hline Klein H2545 & - & 90 & 91 & 36 & - \\
\hline LE 236 & - & 93 & 95 & $42 \mathrm{~s}$ & 21 \\
\hline ND 603 & - & 90 & 96 & 32 & 21 \\
\hline Novosadska Jara & - & 80 & 97 & 30 & 24 \\
\hline OR 1 & Embrapa 27 sib/Bagula sib & $65 \mathrm{~s}$ & 90 & $22 \mathrm{i}$ & 27 \\
\hline PAT 7392 & J 12326-67/IAS 55 & 98 & 96 & 36 & 26 \\
\hline PF 84511 & Butui/PAT 7392 & 90 & 95 & 36 & 24 \\
\hline PF 869114 & CNT 10//Londrina*3/Nyu Bay & $103 \mathrm{i}$ & 93 & 35 & 27 \\
\hline PF 8597 & CNT 9*2/PF 7614//CNT 10/3/2*PF 782021 & 85 & $82 \mathrm{~s}$ & 35 & - \\
\hline PF 86257 & Hulha Negra/CNT 7//Amigo/CNT 7 & 83 & 94 & 30 & - \\
\hline PF 87341 & CNT $8 * 6 /$ Kolibri/3/CNT 8*6/RL 4137 & 83 & 94 & 30 & 27 \\
\hline PF 88490 & BR 8*2/PF 781121 & 88 & 93 & 34 & $31 \mathrm{~s}$ \\
\hline PF 88522 & Minuano 82/PF 79777//Oasis/Jacuí & 85 & 94 & 34 & - \\
\hline PF 88618 & MS 7936/2*BR 2 & 93 & 90 & 37 & 21 \\
\hline PF 889272 & BR $14 * 5 / /$ Londrina*6/FB 6628 & 90 & 90 & 31 & - \\
\hline PF 89156 & Sullivan/PF 79777 & 90 & 95 & 30 & 26 \\
\hline PF 89230 & Cocker $762 / 2 *$ PF 79547 & 80 & 91 & 28 & - \\
\hline PF 89375 & BR $14 * 4 / /$ Jupateco $73 * 4 /$ Amigo sel & 83 & 91 & 31 & 27 \\
\hline PF 89419 & CNT 10//BR 14*2/Largo & 90 & 94 & 29 & $20 \mathrm{i}$ \\
\hline PF 9027 & BR 14/4/PF 839197/3/Londrina/Cocker 76-35//F 20565/F 16955 & 85 & 89 & 30 & - \\
\hline PF 904 & BR 35/PF 84386//Amigo/BR 14 & 83 & 96 & 34 & 26 \\
\hline PF 91602 & $\mathrm{PF} 772003 * 2 / \mathrm{PF} 813$ & 90 & 92 & 29 & - \\
\hline PF 926 & Oasis/BR 5//BR 5/Cocker 762 & 83 & 91 & 31 & - \\
\hline PF 9234 & BR $23 * 2 / \mathrm{PF} 84433$ & 85 & 92 & 28 & 22 \\
\hline PF 92130 & PF $83619 * 2 /$ CEP 17 & 88 & 96 & $41 \mathrm{~s}$ & 27 \\
\hline PF 92349 & Jupateco 73/3*IAC 5//3*PF 782023 & 83 & 89 & 28 & 27 \\
\hline PF 92350 & PF 772003*3//CNT8*3/Sonora 64 & 78 & $82 \mathrm{~s}$ & 33 & - \\
\hline PF 92482 & BR 35*5//BR 14*2/Largo & 88 & 90 & 32 & 25 \\
\hline PF 9343 & Embrapa 27/PF 87107 & 78 & 96 & 30 & 28 \\
\hline PF 93113 & Karim/BR 10 & 90 & $99 \mathrm{i}$ & 30 & \\
\hline PF 93167 & PF 869114/PF 8722 & 85 & $104 \mathrm{i}$ & 30 & 28 \\
\hline PF 940042 & Cocker 762/2*BR 23 & 95 & $102 \mathrm{i}$ & $40 \mathrm{~s}$ & 25 \\
\hline PF 940051 & Italiano/4*BR 2 & 85 & 90 & 33 & - \\
\hline PF 940097 & PF 8619/BR 35 & 90 & 87 & 33 & - \\
\hline PF 940110 & PF 83743/PF 813019//PF 84296/PF 83743 & 95 & 94 & 38 & 25 \\
\hline PF 940262 & Embrapa 27*3//BR 35/Buck Poncho & 88 & $100 \mathrm{i}$ & 37 & 28 \\
\hline PF 940290 & BR 23*2//Embrapa 27/Buck Poncho & 90 & 90 & 28 & - \\
\hline PF 940291 & BR 23/PF 8909 & 90 & 91 & 33 & 26 \\
\hline PF 940301 & BR 35/Klein H2960M12100 & 78 & $85 \mathrm{~s}$ & 29 & - \\
\hline PF 940305 & BR 35/Klein H2960M12100 & 83 & $84 \mathrm{~s}$ & 29 & - \\
\hline
\end{tabular}

$(\mathrm{s})=$ superior e (i)=inferior, em relação a média mais ou menos um desvio padrão.

Ciência Rural, v. 33, n. 5, set-out, 2003. 
Tabela 1 - Continuação.

\begin{tabular}{|c|c|c|c|c|c|}
\hline Genótipos & Pedigree & $\begin{array}{l}\text { Altura } \\
(\mathrm{cm})\end{array}$ & $\begin{array}{l}\text { Ciclo } \\
\text { (dias) }\end{array}$ & $\begin{array}{l}\text { CPed } \\
(\mathrm{cm})\end{array}$ & $\mathrm{N}^{0}$ de grãos \\
\hline PF 940324 & Klein Chamaco/PF 87511 & 90 & 89 & 37 & $35 \mathrm{~s}$ \\
\hline PF 940353 & Embrapa 27*3/Klein H3247A33400 & 85 & $104 \mathrm{i}$ & 36 & $20 \mathrm{i}$ \\
\hline PF 940366 & Embrapa 27*3/Klein H3609B111 & 80 & 93 & 30 & - \\
\hline PF 940374 & Embrapa 27*3/Klein H3609B111 & 80 & 94 & 32 & 26 \\
\hline PF 940384 & Jupateco 73/Embrapa 16 & 78 & 90 & 29 & - \\
\hline PF 940397 & Sonora 64/BR 23 & 88 & 90 & 34 & 23 \\
\hline PF 940398 & Sonora 64/BR 23 & 90 & 90 & 37 & 25 \\
\hline PF 950241 & BR 23*2/PF 83743//PF 87107 & 88 & 92 & 33 & 23 \\
\hline PF 950295 & Embrapa 27/China 7//PF 8908 & $73 \mathrm{~s}$ & 88 & $27 \mathrm{i}$ & 21 \\
\hline PF 950318 & $\mathrm{PF} 88634 / \mathrm{PF} 88522 / / \mathrm{PF} 869120$ & 78 & 90 & 31 & - \\
\hline PF 950338 & PF 869024/PF 88515//CEP 24 & $103 \mathrm{i}$ & 97 & 31 & 25 \\
\hline PF 950351 & BR 32/PF 869120 & 88 & 94 & 33 & $35 \mathrm{~s}$ \\
\hline PF 950354 & Embrapa 16/PAT 7392 & 95 & 90 & 37 & - \\
\hline PF 950407 & BR 35//Embrapa 27/Buck Ombu/3/PF 87511 & 88 & 91 & 30 & 22 \\
\hline PF 960016 & BR 35/Sacaba 81 & 95 & $103 i$ & $42 \mathrm{~s}$ & 22 \\
\hline PF 960018 & Frontana/Sacaba 81 & 88 & $99 \mathrm{i}$ & 34 & 23 \\
\hline PF 960020 & Cocker $762 / 2 *$ BR 23 & 88 & $103 \mathrm{i}$ & 36 & $20 \mathrm{i}$ \\
\hline PF 960170 & Embrapa 27/PF 898//PF 88522 & $73 \mathrm{~s}$ & 91 & 36 & - \\
\hline PF 960177 & PF 87107/Embrapa 40//Embrapa 27/PAT 7392 & 85 & $102 \mathrm{i}$ & 35 & 26 \\
\hline PF 960421 & - & 90 & 94 & 36 & 28 \\
\hline PF 970139 & PF $87511 * 3 /$ Cocker $80-33$ & 85 & 90 & 30 & 25 \\
\hline PF 970183 & PF 87167/PAT 7392//PF 93332 & 93 & 96 & 29 & 24 \\
\hline PF 970241 & PF 86799/SA 8815 & 58 & 90 & $24 \mathrm{i}$ & 24 \\
\hline PF 970366 & Embrapa 27*3/Klein Cartucho//PF 869120/BR 23 & 83 & $99 \mathrm{i}$ & 35 & 26 \\
\hline PF 973571 & Sonora 64*2//Embrapa 16/PF 9099 & $55 \mathrm{~s}$ & 87 & 19i & 22 \\
\hline PF 979020 & BR 23/CEP 8386 & $100 \mathrm{i}$ & 93 & 37 & 23 \\
\hline PF 979037-A & PF 9234/BRS 119 & 83 & 92 & 31 & 23 \\
\hline Pitana & Petiblanco/Floreana & 85 & $82 \mathrm{~s}$ & 33 & - \\
\hline RH 54 & Desconhecido & 95 & 92 & 35 & 28 \\
\hline RS 1 & PF 70100/J 15157-59 & $108 \mathrm{i}$ & 92 & $43 \mathrm{~s}$ & 23 \\
\hline RS 15 & PF $82250 /$ RS 1 & 88 & 90 & 34 & - \\
\hline Rubi & Embrapa 27/Klein H 3450C3131 & 93 & 96 & 28 & $20 \mathrm{i}$ \\
\hline SA 9353 & CEP 8236/RS 1 & 83 & 90 & 37 & 21 \\
\hline Shangai 3 & - & 80 & 90 & 37 & - \\
\hline Sonora 64 & Yaktana 54/Norin 10/BVR/2*Yaqui 54 & $68 \mathrm{~s}$ & $82 \mathrm{~s}$ & $26 \mathrm{i}$ & - \\
\hline Spica-LP 942 & - & 78 & $84 \mathrm{~s}$ & 31 & - \\
\hline Т 50130 & Cook*4/VPM 1 & 78 & 92 & 29 & 24 \\
\hline Trigo de chapéu & Desconhecido & $143 \mathrm{i}$ & $120 \mathrm{i}$ & $54 \mathrm{~s}$ & $20 \mathrm{i}$ \\
\hline Média $(\mu)$ & & 87 & 92 & 33 & 25 \\
\hline Desvio-padrão $(\sigma)$ & & 11 & 6 & 5 & 4 \\
\hline$\mu+\sigma$ & & 98 & 98 & 38 & 29 \\
\hline$\mu-\sigma$ & & 76 & 86 & 28 & 21 \\
\hline
\end{tabular}

$(\mathrm{s})=$ superior e $(\mathrm{i})=$ inferior, em relação a média mais ou menos um desvio padrão.

- genealogia desconhecida

Ciência Rural, v. 33, n. 5, set-out, 2003. 
desenvolvimento de novas cultivares.

Para número de grãos por espiga os genótipos BRS 49, IPF 58950, PF 88490, PF 940324 e PF 950351 apresentaram elevado número de grãos por espiga. Por outro lado, os genótipos Frontana, Karim, Klein H29604-12100, PF 89419, PF 940353, PF 960020 e Rubi apresentaram baixo número de grãos por espiga. Constatou-se que maior número de grãos por espiga não esteve restrito a genótipos de trigo lançados nos anos mais recentes, sendo uma característica relativamente variável.

O genótipo "Trigo de chapéu" destacouse, em valores absolutos, como maior comprimento de pedúnculo, demonstrando que seu difundido uso para fins artesanais é justificado. Outrossim, considerando-se a necessidade de outras características de interesse dos agricultores, como aproveitamento de grãos para fins industriais, outras opções de genótipos com características mais adequadas poderiam ser utilizadas. O genótipo Klein H29604-12100 destacou-se pelo baixo número de grãos por espiga. Este genótipo é procedente da Argentina, sendo utilizado no BC como destaque em qualidade de grão (SILVA et al., 1998).

A altura de planta correlacionou-se positivamente com duração de ciclo até o espigamento e comprimento de pedúnculo, como era de se esperar (Tabela 2). Da mesma forma que as variáveis duração do ciclo até o espigamento e comprimento do pedúnculo mostraram

Tabela 2 - Coeficientes de correlação de Pearson (r) entre as variáveis utilizadas no estudo de genótipos de trigo (Triticum aestivum). Embrapa Trigo, Passo Fundo, 2000

\begin{tabular}{ll}
\hline Variáveis & $\mathrm{r}$ \\
\hline Altura de planta x duração do ciclo até o espigamento & $0,51^{*}$ \\
Altura de planta x comprimento do pedúnculo & $0,69 *$ \\
Altura de planta x número de grãos por espiga & $-0,07 \mathrm{~ns}$ \\
Altura de planta x produtividade & $-0,10 \mathrm{~ns}$ \\
$\begin{array}{l}\text { Duração do ciclo até o espigamento x comprimento do } \\
\text { pedúnculo }\end{array}$ & \\
$\begin{array}{l}\text { Duração do ciclo até o espigamento x número de grãos por } \\
\text { espiga }\end{array}$ & $-0,17 \mathrm{~ns}$ \\
Duração do ciclo até o espigamento x produtividade & $0,13 \mathrm{~ns}$ \\
Comprimento do pedúnculo x número de grãos por espiga & $-0,03 \mathrm{~ns}$ \\
Comprimento do pedúnculox produtividade & $-0,18 \mathrm{~ns}$ \\
Número de grãos por espiga x produtividade & $0,27 \mathrm{~ns}$ \\
\hline
\end{tabular}

* significância em nível de 5\% de probabilidade de erro $\mathrm{ns}=$ não significativo correlação positiva, ou seja, à medida que aumenta a duração do ciclo até o espigamento, aumenta o comprimento do pedúnculo. Observouse que nenhuma das características estiveram relacionadas com a produtividade. Altura de planta e comprimento do pedúnculo mostraram relação independente com o número de grãos por espiga. Era esperado que genótipos modernos, mais baixos, apresentassem maior número de grãos por espiga, visto ter sido o principal responsável pelo aumento do rendimento de grãos nas cultivares modernas (NEDEL, 1994; FRANCO \& CARVALHO, 1987; RODRIGUES, 2000).

Dentre os genótipos que se destacaram por apresentar maior número de grãos por espiga, nenhum destacou-se como menor para altura de planta, não diferindo da média mais ou menos um desvio-padrão. Comportamento semelhante foi observado para o menor número de grãos por espiga. Observando-se a correlação entre comprimento de pedúnculo e número de grãos por espiga, verificou-se que apenas o genótipo "Trigo de Chapéu" apresentou pedúnculo longo e baixo número de grãos por espiga. A grande maioria dos genótipos mostrou comportamento distinto.

Os dados de correlação entre comprimento de pedúnculo e fertilidade de espiga mostraram que, dos 79 genótipos analisados, apenas 11 mostraram correlação significativa entre variáveis (Tabela 3 ). Dentre aqueles, oito genótipos apresentaram correlação positiva e significativa entre comprimento de pedúnculo e

Tabela 3 - Coeficientes de correlação de Pearson (r) entre comprimento de pedúnculo e número de grãos por espiga em genótipos de trigo (Triticum aestivum). Passo Fundo, 1999

\begin{tabular}{lc}
\hline Genótipo & $\mathrm{r}$ \\
\hline BRS 120 & $0,67^{*}$ \\
BRS 179 & $0,63^{*}$ \\
CEP 27 & $-0,70^{*}$ \\
Granito & $-0,70^{*}$ \\
IPF 58950 & $0,63^{*}$ \\
Jacui & $0,63^{*}$ \\
LE 236 & $-0,46^{*}$ \\
ND 603 & $0,72^{*}$ \\
PF 89419 & $0,65^{*}$ \\
PF 940291 & $0,75^{*}$ \\
PF 979020 & $0,63^{*}$ \\
\hline
\end{tabular}

* significância em nível de 5\% de probabilidade de erro

Ciência Rural, v. 33, n. 5, set-out, 2003. 
número de grãos por espiga, enquanto três genótipos mostraram uma correlação negativa entre as variáveis. A cultivar Jacuí, embora portadora de pedúnculo longo e altura de planta elevada, apresentou correlação positiva entre comprimento do pedúnculo e fertilidade de espiga, enquanto Granito, classificada entre as de menor pedúnculo, apresentou correlação negativa.

Os resultados indicam a existência de grande variabilidade genotípica quanto às características avaliadas. Entretanto, as informações são relativas a um ano de avaliação e as mesmas são afetadas pelas condições ambientais, podendo apresentar variação maior ou menor em outros anos (SILVA et al., 1998). Dessa forma, os resultados obtidos representam importante subsídio que poderão ser utilizados por melhoristas, na seleção de genitores, por técnicos da extensão rural, e por agricultores na escolha de genótipos de trigo para fins artesanais.

\section{CONCLUSÕES}

Os genótipos de trigo BR 18, BR 42 e Sonora 64 destacam-se por porte baixo e ciclo precoce; enquanto Florida 301 e "Trigo de chapéu" destacam-se por porte alto e ciclo longo até o espigamento.

A altura de planta mostra alta correlação com comprimento do pedúnculo e duração do ciclo até o espigamento e esta com o comprimento pedúnculo.

Os genótipos de trigo CNT 10 e PF 92130 são indicados com finalidades artesanais por suas características de pedúnculo longo e número de grãos por espiga acima da média.

Existe grande variabilidade genética entre os genótipos de trigo quanto às características avaliadas, fornecendo subsídios que poderão ser utilizados por melhoristas, técnicos e agricultores.

\section{REFERÊNCIAS BIBLIOGRÁFICAS}

AUSTIN, R.B.; FORD, M.A.; MORGAN, C.L. Genetic improvements in the yield of winter wheat: further evaluation. Journal Agricultural Science, v.112, p.295$301,1989$.

COX, T.S. et al. Genetic improvement in agronomic traits of hard red winter wheat cultivars from 1919 to 1987 . Crop Science, v.28, p.756-760, 1988.
CRUZ-AGUADO, J.A. et al. Effect of source-to-sink ratio onf partitioning of dry matter and c-photoassimilates in wheat during grain filling. Annals of Botany, v.83, p.655-665, 1989.

FRANCO, F. de A.; CARVALHO, F.I.F. Progresso genético no rendimento do trigo e sua associação com diferentes caracteres sob variações ambientais. Pesquisa Agropecuária Brasileira, Brasília, v.22, n.3, p.311-321, 1987.

LINHARES, A.G.; SOUSA, C.N.A.; ZANATTA, A.C.A. Catalog of wheat germplasm. Passo Fundo: EMBRAPA-CNPT, 1997. 80p. (EMBRAPA-CNPT. Documentos, 31).

NEDEL, J.L. Progresso genético no rendimento de grãos de cultivares de trigo lançadas para cultivo entre 1940 e 1992. Pesquisa Agropecuária Brasileira, v.29, n.10, p.1565-1570, 1994.

REUNIÃO DA COMISSÃO SUL-BRASILEIRA DE PESQUISA DE TRIGO, 31., 1999, Passo Fundo. Ata... Passo Fundo : Embrapa Trigo, 1999. 131p.

RODRIGUES, O. Manejo de trigo: bases ecofisiológicas. In: CUNHA, G.R.; B ACAltChuK, B. (Org). Tecnologia para produzir trigo no Rio Grande do Sul. Porto Alegre: Assembléia Legislativa. Comissão de Agricultura Pecuária e Cooperativismo / Passo Fundo : Embrapa Trigo, 2000. 404p. (Série Culturas, n. 02).

SHAKIBA, M.R. et al. Contribution of internode reserves to grain yield in a tall and semi-dwarf spring wheat. Jounal of Genetic Breeding, v.50, p.91-100, 1996.

SIDDIQUE, K.H.M.; KIRBY, E.J.M.; PERRY, M.W. Ear:stem ratio in old and modern wheat varieties, relationship with improvement in number of grains per ear and yield. Field Crops Research, v.21, p.59-78, 1989.

SILVA, S.A. et al. Informações sobre os genótipos do bloco de cruzamentos de trigo do CNPT em 1990. Pesquisa Agropecuária Brasileira, v.33, número especial, p.565588,1998

SLAFER, G.A.; ANDRADE, F.H. Changes in physiological attributes of the dry matter economy of bread wheat (Triticum aestivum) through genetic improvement of grain yield potential at different regions of the world. Euphytica, v.58, p.37-49, 1991.

SOUSA, C.N.A. Relação das cultivares comerciais de trigo no Brasil de 1922 a 1997. Passo Fundo : Embrapa-CNPT, 1997. 46p. (Embrapa-CNPT. Documentos 39).

STATISTAL ANALYSIS SYSTEM INSTITUTE. SAS User's Guide Statistic. Version 5. Cary : SAS, 1985. 
ZAFFARONI, E.A. et al. Análise de caminho nos componentes de rendimento de genótipos de arroz no Rio
Grande do Sul. Pesquisa Agropecuária Brasileira, v.33, n.1, p.43-48, 1998.

Ciência Rural, v. 33, n. 5, set-out, 2003. 